\title{
An Investigation of the Relationship between Personality Dimensions and General Health of High School Female Students in Falavarjan City
}

\author{
Moradi Qahderijani ${ }^{1}$, Mahboubeh, Karami ${ }^{2}$, Fatemeh, Norouzi, Mohsen ${ }^{3}$
}

\section{ABSTRACT}

Application of psychological principles for promoting the quality of education is a scientific method. High quality and proper education is not possible without considering individual differences and understanding individuals' states and traits, whether students or teachers. This study has been conducted to examine the relationship between personality dimensions and mental health of high school students. The statistical population of the study consisted of all high school students in Falavarjan city from which a sample of 100 individuals were selected. They were then studied through (NEO) Personality Inventory and the General Health Questionnaire (GHQ). The findings of the study have been analyzed and they were reported as descriptive statistics and correlational study by SPSS software. The results showed that there is a significant relationship between personality dimensions and general health of high school female students in Falavarjan city.

Keywords: Personality Dimensions, Personality Trait, General Health, Mental Health, Student

\section{OBJECTIVES}

Using the psychological principles for improving the quality of education is a scientific method. High quality and proper education is not possible without considering individual differences and understanding individuals' states and traits, whether students or teachers. The concepts of personality and mental health are among the words most commonly used in psychology and thus, studying the relationship between them can help to a better understanding of individual differences [1].

An efficient educational system should provide the necessary conditions for talents to flourish with respect to students' differences [2].

Individual differences among humans have long been a topic of interest to psychologists. These studies started from examining the physical appearance (body measurement such as height, weight, etc.) and they were then extended to attributing personality traits to physical

\footnotetext{
${ }^{1}$ M.Sc. in Clinical Psychology, University of Payame Noor, Isfahan, Qahderijan, Iran

${ }^{2}$ B.Sc. in General Psychology, University of Payame Noor, Isfahan, Qahderijan, Iran

${ }^{3}$ B.Sc. in Health Care Management, Isfahan University of Medical Sciences and Health Services (IUMS), Iran (C) 2015 I M Mahboubeh, K Fatemah, N Mohsen; licensee IJIP. This is an Open Access Research distributed under the terms of the Creative Commons Attribution License (http://creativecommons.org/licenses/by/2.0), which permits unrestricted use, distribution, and reproduction in any Medium, provided the original work is properly cited.
} 


\section{An Investigation of the Relationship between Personality Dimensions and General Health of High School Female Students in Falavarjan City}

characteristics (the physical appearance). Then, the studies shifted to senses, and from senses to perception, from perception to cognition, and from cognition to cognitive components and processes (attention, perception, processing, memory, etc.) [3].

One of the most important factors affecting students' academic achievement is their psychological and personality traits. Every individual is equipped with tools such as psychological structures and personality characteristics in order to enter the society and thus to deal with different situations and different people (in terms of culture, social class, etc.) [4]. These psychological tools can help him to deal with different aspects of his life. These psychological structures are not only affected by factors such as family, society, peers, etc., but they also influence these factors reciprocally [5]. These personality characteristics are indeed assumed as mood stimuli for achieving the goals, i.e. these characteristics prompt humans to perform different behaviors in certain situations [6].

\section{THEORETICAL FOUNDATIONS OF THE RESEARCH:}

Personality dimensions: They are multiple personality traits or characteristics of individuals, i.e. a series of informal types, each of which represent a set of different characteristics. Psychologists have proposed numerous methods for classifying the personalities into various types. For example, the Swiss psychologist Carl Jung believed that people are either introvert or extrovert. Extroverted people are sociable, pushy and outward-oriented. But introverted people are shy and selfcontained. In general, these classifications are inadequate and cannot show personality differences. That's why categorizing people based on a list of characteristics provides more information when compared to classifying them into two or three personality types [7]. In this study, individuals' personality dimensions have been determined through the scores they obtained in Big Five Personality Test. These scores were measured by the NEO Personality Inventory.

General health: According to The World Health Organization definition, health is the physical, mental, and social soundness and vigor and not only being free from illness, but also productivity (efficiency). The functional, comprehensible, and appreciable part of this definition is not being sick. As defined by WHO, health is a state of complete physical, mental and social well-being and not merely the absence of disease [8]. In this study, individuals' general health has been determined through the scores they obtained in the general health test by a questionnaire.

\section{LITERATURE REVIEW:}

Hayes and Joseph [9] have shown that high scores on each of the mental health tools are associated with the personality dimensions. McCrea and costa [10] have shown that personality dimensions are associated with happiness and mental health. In other researches, they have also shown that individuals with high scores on personality dimensions have better mental health than those with low scores on these dimensions. Costa and McCrae [11] showed that happiness is correlated with high level of extraversion and low level of neuroticism. Chan and Joseph [12] have also confirmed this relationship in their study. Dastourani [13] investigated the personality characteristics and mental health of employees and indicated that conscientiousness and mental 


\section{An Investigation of the Relationship between Personality Dimensions and General Health of High School Female Students in Falavarjan City}

health are positively correlated with employees' job satisfaction. Based on the results of the study by Ahadi [14] who examined the relationship between personality characteristics and mental health, there is a significant relationship between personality factor of dutifulness and mental health. It was also indicated that dutifulness is significantly contributed to the prediction and explanation of Mental Health. In other words, the increase in dutifulness is associated with more mental health. The research by Bakhshayesh [15] who examines the relationship between the general health and the personality types, and employees' job satisfaction in the health center of Yazd city, showed that general health, neuroticism, extraversion and agreeableness are correlated. Moreover, their subscales are also related.

\section{METHOD}

This is an applied study which used a descriptive research technique. Considering that personality characteristics and mental health are, respectively, the predictive variable and criterion variable in this study, the descriptive correlational method was used for the data collection.

Statistic population: Statistic population of the study consisted of all high school female students (Humanities, Experimental sciences, mathematics \& physics, and vocational and technical training) who have been studying in high schools of Falavarjan city during the 2013-14 academic year.

Samples selection and sampling method: Tajadod high school of Largan was selected randomly from among the mentioned population which included 100 high school students.

Study Tools: Tools used in this study included the NEO Personality Inventory test and general health test.

NEO Personality Inventory: NEO-FFI personality questionnaire is the 60 -item truncated version of NEO PI-R which has been designed for quick and brief assessment of the five major factors (neuroticism, extraversion, openness, agreeableness and conscientiousness). It is comprised of five sets of 12-item for each indicator in which grading is based on the five-point Likert scale from strongly disagree to strongly agree. This questionnaire is applicable individually or in group and the testing environment should be comfortable, quiet and light.

Reliability and validity: In regard to the validity of the test, the results of several studies suggest that the NEO FF- sab-scales have a good internal consistency. Retest reliability coefficients of scales varied from $30 / 0$ to $65 / 0$ for time spans of three months [16].

GHQ-28 Mental Health Questionnaire: This questionnaire was developed to identify nonpsychotic mental disorders and it is widely used for the diagnosis of mild mental disorders and screening for non-psychotic psychiatric disorders in health centers and other communities in 
various situations. The response of subjects to each question will be determined in a range of four degrees. The 28-item was developed using factor analysis on the full-length version and consists of 4 scales, each scale with 7 questions. Scales include: 1) physical symptoms, 2) anxiety and sleep disorders, 3) social dysfunction 4) severe depression.

Questionnaire reliability: Reliability coefficient of GHQ-28 questionnaire is 0.781 in the statistics population. This is a high reliability and proves that this test is valid.

Data Collection Methods: 100 copies of the questionnaire were presented after preparation and then they were brought to a high school and given to the students. Once the questionnaires were completed, the data were scored and analyzed. This phase of the study lasted one week.

Data analysis: The analysis methods included frequency, mean, standard deviation, minimum and maximum, Pearson correlation coefficient, and correlation diagrams. Data analysis was performed using SPSS V17 software.

\section{RESULTS}

The present study investigated students' mental health and types of personality dimensions. In this study, 100 high school students were evaluated using simple random selection. The findings which were analyzed using statistical methods are as follows based on the research questions:

Based on the results of the descriptive investigation on the 5 personality factors (Table 1), it can be observed that the neuroticism dimension has the highest mean, i.e. 24.5, and the conscientiousness dimension has the lowest mean, i.e. 21.5 in the case under study.

Table 1: Descriptive data of personality variables, along with their subscales on high school students in Falavarjan city in 2014

\begin{tabular}{|l|c|c|c|c|c|c|}
\hline & Neuroticism & Extraversion & Openness & Agreeableness & Conscientiousness & Personality \\
\hline N Valid & 100 & 100 & 100 & 100 & 100 & 100 \\
Missing & 0 & 0 & 0 & 0 & 0 & 0 \\
Mean & 24.5000 & 22.8400 & 23.0200 & 22.1300 & 215000 & 114.3300 \\
Median & 25.0000 & 23.5000 & 23.0000 & 23.0000 & 22.5000 & 115.0000 \\
Mode & 22.00 & 24.00 & 22.00 & 25.00 & 23.00 & 113.00 \\
Std. & 4.66991 & 4.66822 & 3.29057 & 5.05256 & 6.85713 & 14.11787 \\
Deviation & 21.808 & 21.792 & 10.828 & 25.528 & 47.020 & 199.314 \\
Variance & 11.00 & 9.00 & 12.00 & 7.00 & 0.00 & 57.00 \\
Minimum & 34.00 & 34.00 & 31.00 & 31.00 & 34.00 & 142.00 \\
Maximum & \multicolumn{7}{r}{}
\end{tabular}


The results in table 2 show that the general health score is 36.49. With regard to the fact that the individual's general health score ranges from 0 to 84 , in such a way that a lower score indicates a better general health, thus, subjects' mean in this study represents the minimum general health, i.e. individuals have psychological problems.

Table 2: Descriptive data of mental health, along with its subscales on high school students in Falavarjan city in 2014

\begin{tabular}{|c|c|c|c|c|c|c|}
\hline & & $\begin{array}{l}\text { Physical } \\
\text { function }\end{array}$ & $\begin{array}{l}\text { Anxiety and } \\
\text { sleep disorder }\end{array}$ & $\begin{array}{l}\text { Social } \\
\text { function }\end{array}$ & Depression & $\begin{array}{l}\text { General } \\
\text { health }\end{array}$ \\
\hline $\mathrm{N}$ & Valid & 100 & 100 & 100 & 100 & 100 \\
\hline & Missing & 0 & 0 & 0 & 0 & 0 \\
\hline & & 9.3100 & 9.1000 & 8.0300 & 10.3400 & 36.4900 \\
\hline & & 9.0000 & 9.0000 & 8.0000 & 11.0000 & 36.0000 \\
\hline & & (a) 8.00 & 8.00 & 9.00 & 13.00 & 39.00 \\
\hline & & 4.49398 & 4.08125 & 3.34076 & 5.35643 & 14.19667 \\
\hline & & 20.196 & 16.657 & 11.161 & 28.691 & 201.545 \\
\hline & & 1.00 & 2.00 & 2.00 & 0.00 & 8.00 \\
\hline & & 18.00 & 18.00 & 15.00 & 21.00 & 66.00 \\
\hline
\end{tabular}

According to table 3 and diagram 1, the correlation coefficient for the neuroticism dimension is 0.025. Thus, it has a significant negative correlation with mental health. In other words, the more neurotic a person is the better mental health he has. But this correlation is weak.

Table 3: Results of the Pearson correlation coefficient on the relationship between neuroticism and general health

\begin{tabular}{|c|c|c|c|}
\hline & & Neuroticism & General health \\
\hline \multicolumn{2}{|c|}{ Neuroticism Pearson } & 1 & (-) 0.025 \\
\hline \multirow{5}{*}{$\begin{array}{l}\text { General } \\
\text { health }\end{array}$} & Sig. (2-tailed) & & 0.805 \\
\hline & $\mathrm{N}$ & 100 & 100 \\
\hline & Pearson & (-) 0.025 & 1 \\
\hline & Sig. (2-tailed) & 0.805 & \\
\hline & $\mathrm{N}$ & 100 & 100 \\
\hline
\end{tabular}




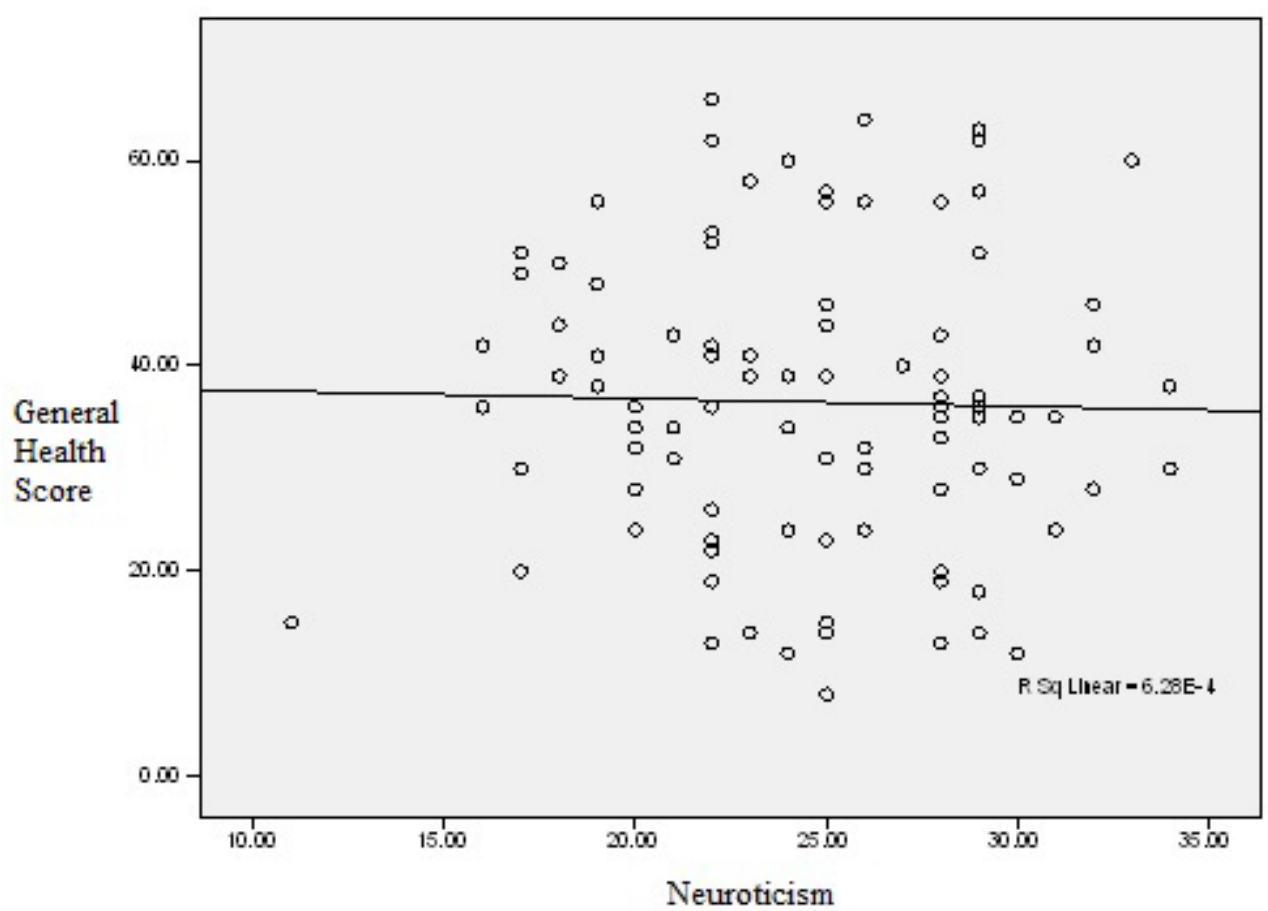

Diagram 1: The scatter plot displaying the negative correlation between two neuroticism and general health

The results in table 4 and diagram 2 indicate that the correlation coefficient for extraversion is 0.384. And therefore, it has a significant positive correlation with mental health. In other words, as level of extraversion increases, mental health decreases. This is considered a moderate correlation.

Table 4: Results of the Pearson correlation coefficient for the relationship between extraversion and general health

\begin{tabular}{|ll|c|c|}
\hline & & Extraversion & General health \\
\hline Extraversion & Pearson & 1 & $0.384(* *)$ \\
& Correlation & & 0.000 \\
& Sig. (2-tailed) & & 100 \\
& $\mathrm{~N}$ & 100 & 1 \\
General health & Pearson & $0.384(* *)$ & 100 \\
& Correlation & 0.000 & 100 \\
& Sig. (2-tailed) & $\mathrm{N}$ & \\
\hline
\end{tabular}




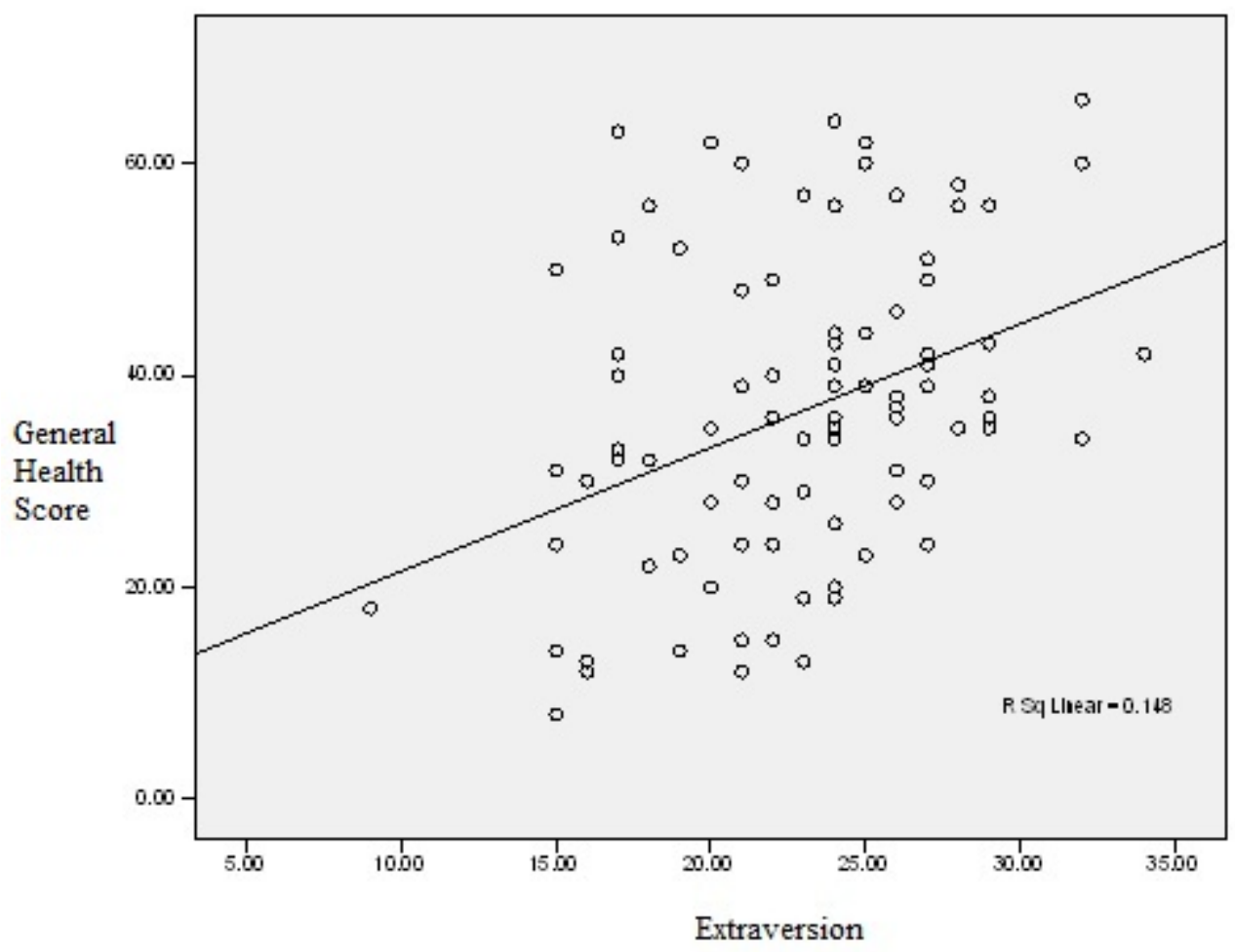

Diagram 2: Scatter plot displaying the positive correlation between extraversion and general health

The findings of the study also showed that the openness dimension has a correlation coefficient of -0.051 . And thus, it has a significant negative correlation with mental health. In other words, the more open a person is, the better is his mental health. This is a weak correlation (Table 5 and diagram 3).

Table 5: Results of the Pearson correlation coefficient on the relationship between openness and mental health.

\begin{tabular}{|ll|c|c|}
\hline & & Openness & General health \\
\hline Openness & Pearson & 1 & $(-) 0.051$ \\
& Correlation & & 0.613 \\
& Sig. (2-tailed) & & 100 \\
General health & N & 100 & 1 \\
& Pearson & $(-) 0.051$ & \\
& Correlation & 0.613 & 100 \\
& Sig. (2-tailed) & 100 & \\
& N & & \\
\hline
\end{tabular}




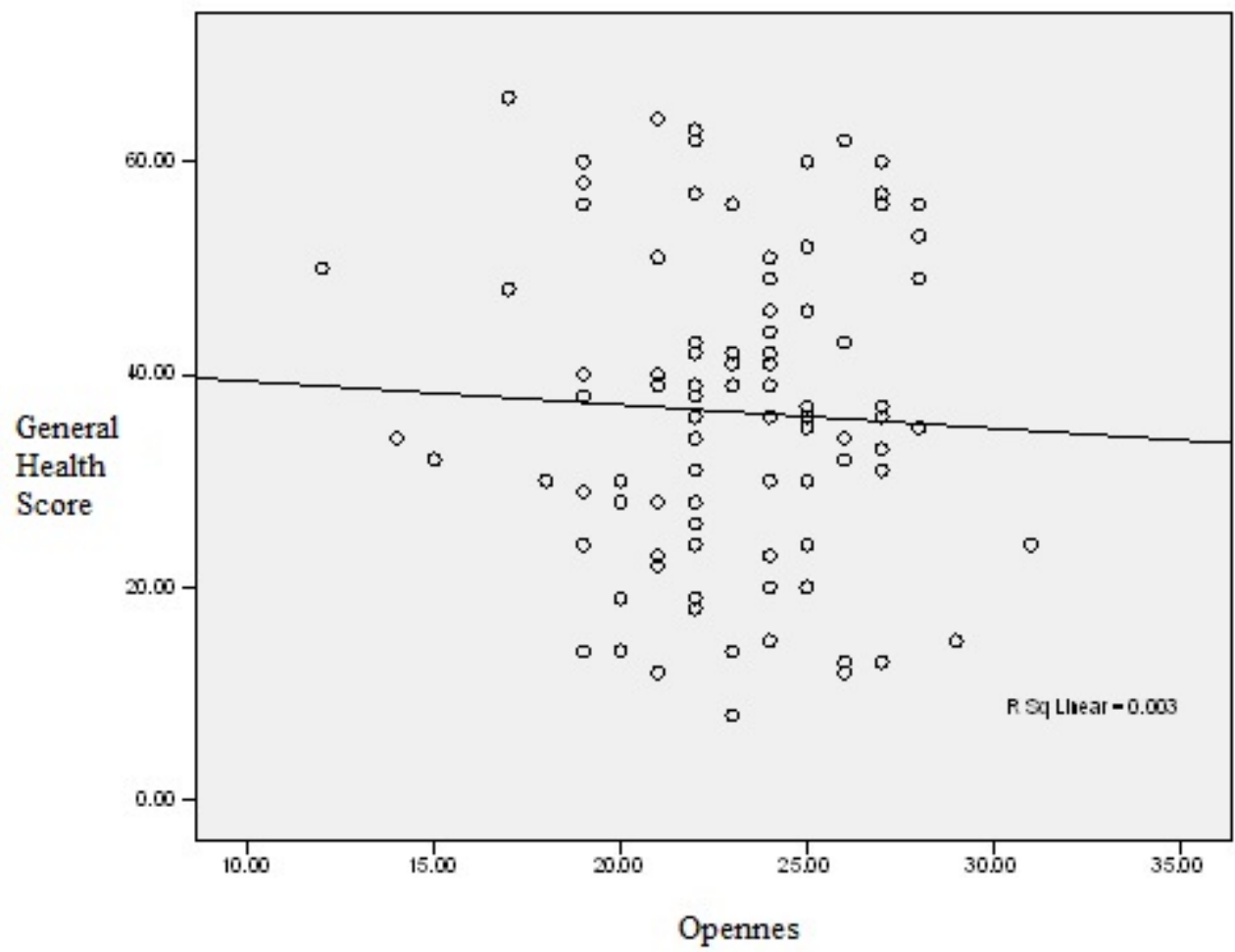

Diagram 3. Scatter plot displaying the negative correlation between openness and general health.

The results also showed that agreeableness dimension has a correlation coefficient of 0.194 . And therefore, it has a significant positive correlation with mental health. In other words, the more agreeable a person is, his mental health gets worse. And this correlation is a weak one (Table 6 and Diagram 4).

Table 6: Results of the Pearson correlation coefficient on the relationship between agreeableness and general health.

\begin{tabular}{|ll|c|c|}
\hline & & Agreeableness & General health \\
\hline Agreeableness & Pearson & 1 & 0.194 \\
& Correlation & & 0.053 \\
& Sig. (2-tailed) & & 100 \\
& N & 100 & 1 \\
General health & Pearson & 0.194 & \\
& Correlation & 0.053 & 100 \\
& Sig. (2-tailed) & 100 & \\
N & &
\end{tabular}




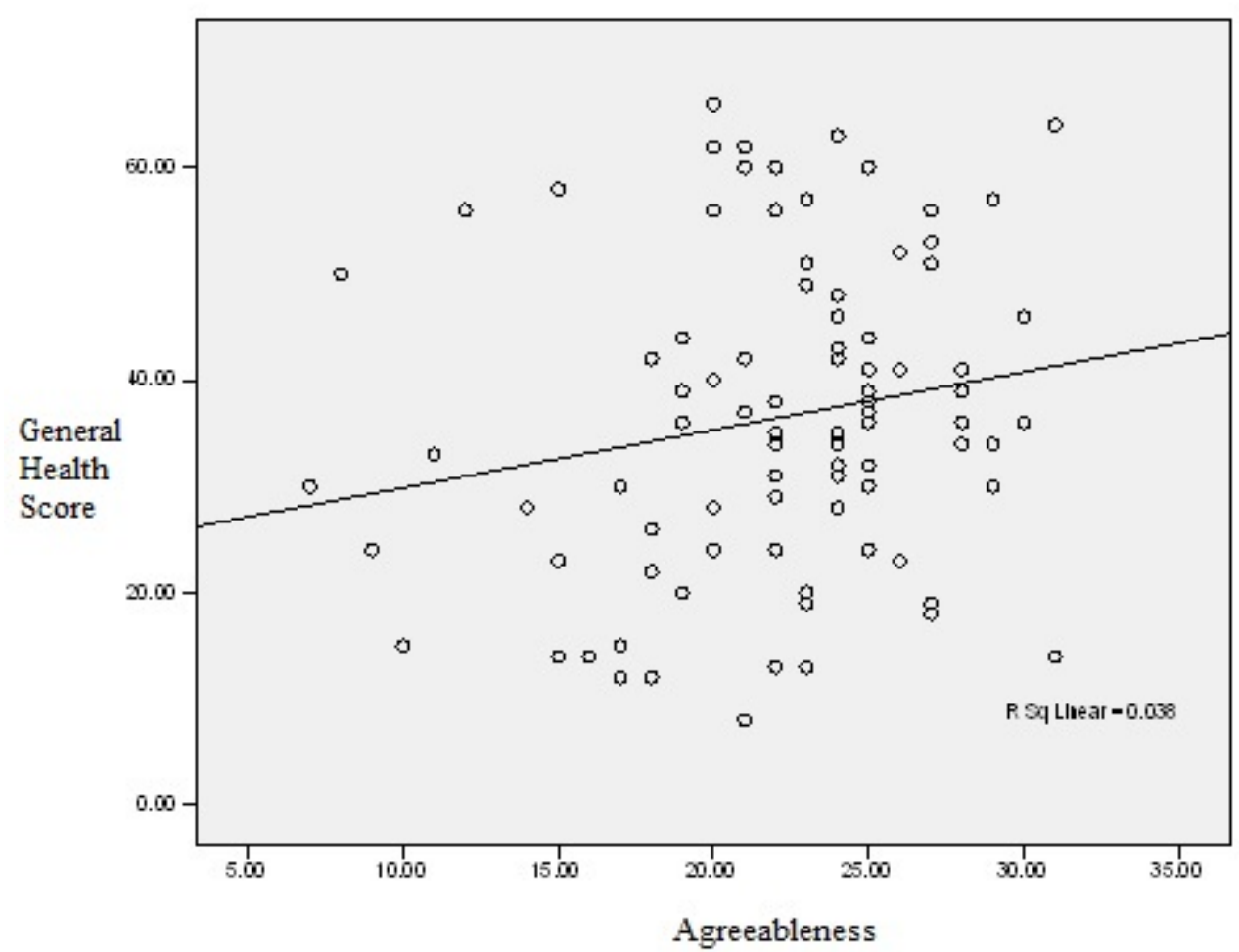

Diagram 4: Scatter plot displaying the positive correlation between agreeableness and general health

Based on the results in table 7 and diagram 5, conscientiousness dimension, with a correlation coefficient of 0.427 , has a significant positive correlation with mental health. In other words, as conscientiousness increases, mental health gets worse. Meanwhile, this is a moderate correlation.

Table 7: Results of the Pearson correlation coefficient on the relationship between conscientiousness and general health

\begin{tabular}{|c|c|c|c|}
\hline & & Conscientiousness & General health \\
\hline \multirow[t]{2}{*}{ Conscientiousness } & $\begin{array}{l}\text { Pearson } \\
\text { Correlation }\end{array}$ & 1 & $0.427(* *)$ \\
\hline & $\begin{array}{l}\text { Sig. (2-tailed) } \\
\mathrm{N}\end{array}$ & 100 & $\begin{array}{c}0.000 \\
100\end{array}$ \\
\hline \multirow[t]{3}{*}{ General health } & Pearson & $0.427(* *)$ & 1 \\
\hline & Sig. (2-tailed) & 0.000 & \\
\hline & $\mathrm{N}$ & 100 & 100 \\
\hline
\end{tabular}




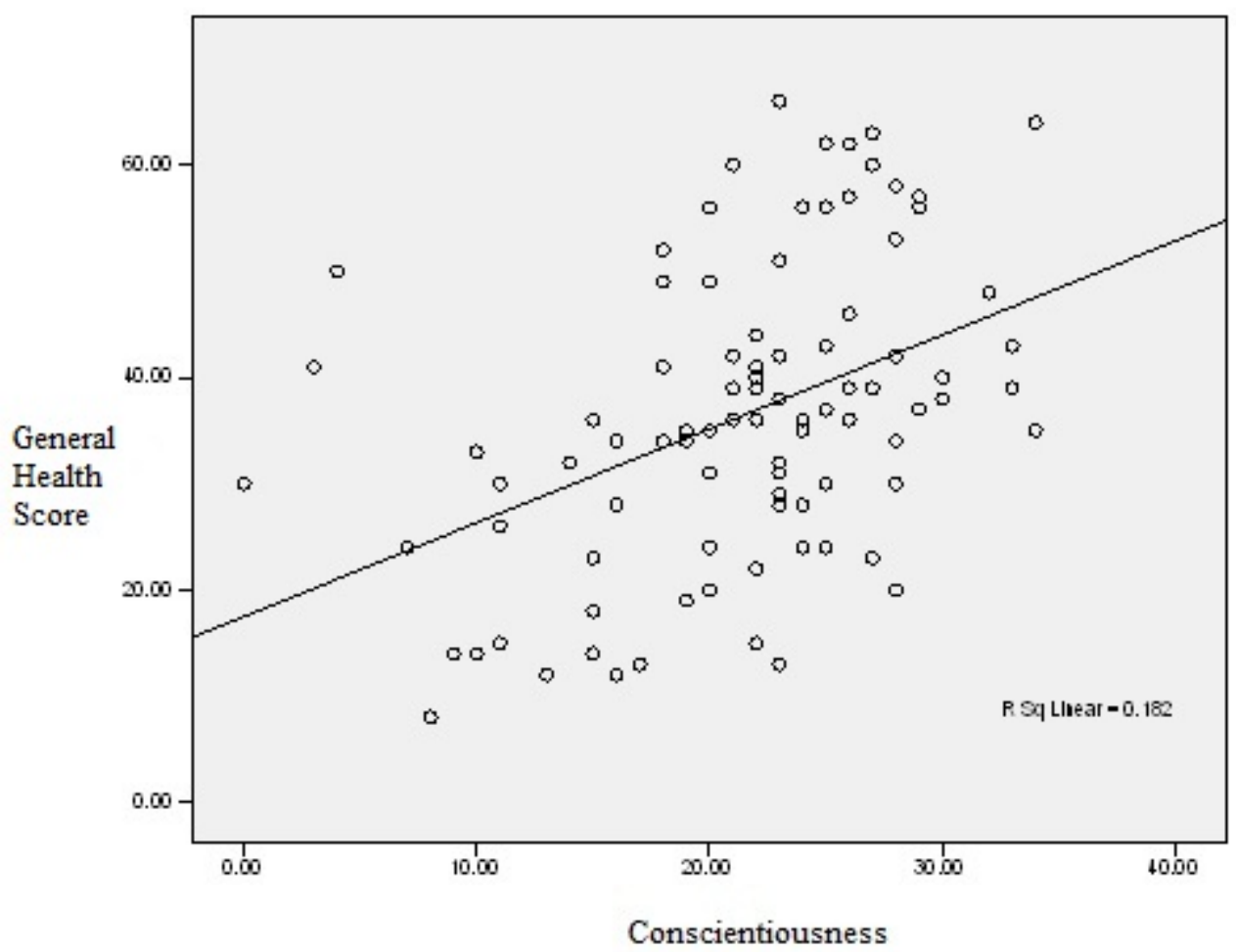

Diagram 5: Scatter plot displaying the positive correlation between conscientiousness and general health

The result of the study also showed that personality factor with a correlation coefficient of 0.386 has a significant positive correlation with mental health. In other words, the higher score a person obtains on the personality test, the worse mental health he has. This correlation is a moderate one (Table 8 and Diagram 6).

Table 8: Results of the Pearson correlation coefficient on the relationship between personality and mental health

\begin{tabular}{|ll|c|c|}
\hline & & Personality & General health \\
\hline Personality & Pearson Correlation & 1 & $0.386\left(^{* *}\right)$ \\
& Sig. (2-tailed) & & 0.000 \\
& N & 100 & 100 \\
General health & Pearson Correlation & $0.386(* *)$ & 1 \\
& Sig. (2-tailed) & 0.000 & 100 \\
\hline & N & 100 & 100 \\
\hline
\end{tabular}




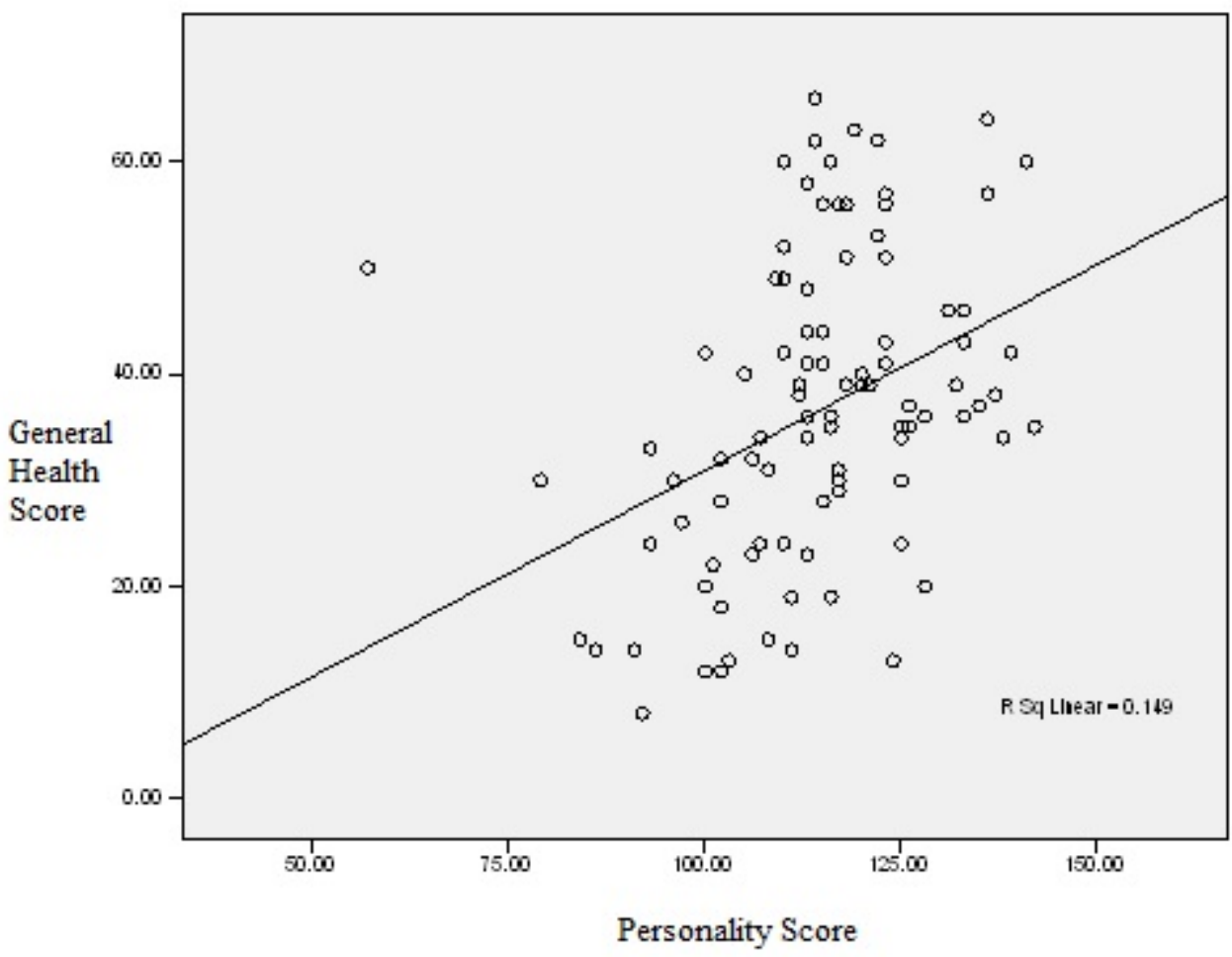

Diagram 6: Scatter plot displaying the positive correlation between personality and general health.

\section{DISCUSSION}

According to the findings of the research, there is a significant negative correlation between the general health and neuroticism. Thus, the first hypothesis of the study, i.e. there is a significant correlation between the general health and neuroticism is confirmed.

The second hypothesis was also confirmed. The reason is that based on the findings of the study, there is a significant positive correlation between extraversion and general health.

The findings of the study also confirm that the "there is a significant relationship between openness and general health." This is due to the fact that a significant negative correlation was observed between openness and general health.

DeNeve and Cooper [17], conducted a research on the relationship between personality and openness and indicated that people with high levels of openness show a friendly, kind and caring behavior even in stressful situations. These findings are consistent with the results of the study by McCrae and Costa [10], on the five factors of personality and mental health. In their study, they showed that people with high levels of openness show greater emotional health than those with low levels of this trait. 


\section{An Investigation of the Relationship between Personality Dimensions and General Health of High School Female Students in Falavarjan City}

According to the findings of the present study, it is confirmed that there is a significant relationship between agreeableness and general health due to the significant positive correlation between them.

In this study, although there was no significant relationship between openness to experience and mental health, as McCrae and Costa [18], have expressed, openness to experience is the most complex factor among the five major personality factors and thus, it is hard to understand and recognize it [19]. Thus, more studies should be conducted for the accurate understanding and cognition of the dynamics and complexities of this factor.

Also according to the findings, there is a significant positive relationship between conscientiousness and general health. Thus, the fifth hypothesis, i.e. there is a significant relationship between the conscientiousness and general health, is also confirmed.

Every sound human being of mental health accepts responsibility of his life and behavior; behaves normally and in responsible ways; faces the realities realistically; and decides based on logic and emotion. Thus, according to the five-factor model of personality [16], it can be inferred that since conscientious people have some sort of perseverance, self-discipline, orderliness, and mostly they are accurate, reliable and reasonable, conscientiousness is an important factor to predict life satisfaction, and life satisfaction emphasizes on the cognitive aspects and value of mental health.

\section{CONCLUSION}

Mental health experts believe that mental health not only requires being free from a mental illness, but also it is the ability to react to a variety of life experiences in an open and significant way. Mental health is a combination of positive emotions and positive performance. It is associated with the presence of prosperity and absence of weakness and lassitude. One of the concepts which is observed in the studies related to the students is their mental health problems.

Recent studies show that more mental health problems are observed in students as countries are getting industrialized. Stresses related to their age, biological maturity problems, adaptability to new ways of life and education, behaviors with peers, participation in groups and staying away from family are among the factors which will increase students' stress. Spiritual concepts and existential problems, uncertainty about values, lack of connections and longing for family are some of stressful factors in students which reduce their health level. One on the most important consequences of students' health level reduction is the emergence of various problems such as educational failure. Therefore, studying the factors affecting the health of students and how they cope with the stresses and pressures of student life is necessary for improving their educational quality and enhancing the scientific level of school. 


\section{An Investigation of the Relationship between Personality Dimensions and General Health of High School Female Students in Falavarjan City}

Based on the results of this study and other similar studies, students' personality characteristics are related to their health. The relationship between personality characteristics is applicable in a wide range of areas including the prediction of behavioral problems. A significant point that should be noted is that students' personality, whether extroverted or neurotic, is related to their mental health. At first glance, it is the personality of an individual which must be considered. Any type of personality has its own sets of performances and responses. Considering this point, we can communicate with people properly and easily. In a study by Steel, Shultz, \& Schmidt in 2008 [20], through reviewing previously conducted researches on the relationship between personality characteristics and welfare, it has been observed that personality traits explain 39 to 63 percent of the variance of welfare.

Totally, the results of the present research support this view that personality characteristics can provide preparation and effective potential context for individuals’ mental health.

Given the enormous difficulties and pressures with which students are facing, the need for planning for the purpose of solving their future problems, promoting their mental health, and consequently improving the scientific level of the country is felt more than ever. According to the findings of the present study, among the most important and effective ways of improving students' health are relieving the pressure on them, increasing their ability to deal with problems, finding meaning in life, and strengthening the foundations of mental health. Thereupon, conducting further researches, planning, and implementation of interventions in this area seems essential. It is also recommended that studies be undertaken to assess personality dimensions and male students' mental health. Also, it is suggested that other personality variables related to the general health be studied in future studies.

\section{REFERENCES}

Ahadi, B., (2008). The relationship between personality traits and mental health. Journal of Educational Sciences Studies, 1 (2): 7-18

Aliabadi, Kh. (2003). Dunn and Dunn and Price Learning Style Inventory normalization, and comparison of the third and fifth grade students' learning styles in Tehran, Ph.D. thesis, Faculty of Psychology and Educational Sciences, Allameh Tabatabai Univ., Tehran, Iran.

Alipour, A., (2010). Introduction to psychology, Salamt. Tehran: PNU.

Bakhshayesh, A., (2013). An investigation of the relationship between the general health, the type of personality and job satisfaction among health care workers in Yazd city. Tehran: Journal of Paramedical Sciences (Payavard Salamat), 7 (1): 42-55.

Barry, R. A, Lakey, B, Orehek, E., (2007). Links among attachment dimensions, affect, the self, and perceived support for generalized attachment stylsand specific bonds. Personality and Social Psychology Bulletin (PSPB), 33 (3), 340-357. 


\section{An Investigation of the Relationship between Personality Dimensions and General Health of High School Female Students in Falavarjan City}

Chan, R. Joseph, S., (2000). Dimensions of personality domains of aspiration, and subjective well-being. Personality and Individual Differences, 28 (2): 347-354

Costa P.T., Jr., and McCrae R.R. Revised NEO Personality Inventory (NEO PI-R) and the NEO Five-Factor Inventory (NEO-FFI) professional manual. Odessa, FL: Psychological Assessment Resources; 1992.

Dastourani, M., (2012). An investigation of the relationship between personality traits, mental health and job satisfaction. M.A. thesis, Tarbiat Modares Univ., Tehran, Iran.

DeNeve, K., \& Cooper, H. (1998). The happy personality: A meta-analysis of 137 personality traits and subjective well-being. Psychological Bulletin, 124 (2), 197-229.

Ebadi, A., (2005). The relationship between personality traits and learning styles of high school first grade students. M.A. thesis, Shahid Beheshti University., Tehran, Iran.

Ganji, H., (1991). Psychometrics and Theoretical Foundations of psychological tests. Tehran: PNU.

Hayes. N. Joseph .S. (2003). Big 5 correlates of three measures of subjective well-being. Personality and individual differences, 34 (4): 723-727.

Kemmelmeier, M., Danielson, C., g Bastten, J., (2005). Whats in grade? Academic success and political orientation .Personality and Social Psychology Bulletin (PSPB), 31 (10): 13861399.

Lawrence, P., (1996). Personality psychology. Translated by Javadi, M.J. and Kadivar, P. (1995), first edition. Tehran: Rasa Cultural Institute Publication.

McCrae, R .R. Costa P. T., (1991). Adding Liebe und Arbeit: the full five factor model and wellbeing. Personality and Social Psychology Bulletin (PSPB), 17 (2): 227-232.

McCrae, R. R., g Costa. Jr. P. T., (1986). Personality coping and coping effectiveness in an adult sample. Journal of personality, 54 (2): 385-405.

Parker, J. D., Babgy, R. M., Tylor, G. J., (1989). Toronto Alexithymia scale, EPQ and self-report measures of somatic complaints. Personality and Individual Differences, 10 (6): 599604.

R. R. McCrae and P. T. Costa Jr., "Conceptions and Correlates of Openness to Experience,” In: R. Hogan, J. A. Johnson and S. R. Briggs, Eds., Handbook of personality psychology, Academic Press, New York, 1996, pp. 825-847.

Seyed Kamali, S. M., (1999). Educational leadership and management. Tehran: Ramin publication.

Steel, P., Schmidt. J. Shultz, J., (2008). Refining the relationship between personality and subjective well-being. Psychological Bulletin, 134 (1): 138-161. 